THEIR PEERS

This is the peer reviewed version of the following article: Jupe, L. M., Akehurst, L., Vernham, Z., \& Allen, J. (in press). Teenage Offenders' Ability to Detect Deception in Their Peers. Applied Cognitive

Psychology, which will be published in final form at

http://onlinelibrary.wiley.com/journal/10.1002/(ISSN)1099-0720.

This article may be used for non-commercial purposes in accordance with Wiley Terms and Conditions for Self-Archiving.

Summary: This study investigated the deception detection abilities of teenage offenders and teenage non-offenders who made veracity judgments about 12 videotaped interviewees, and also explored the behavioural characteristics of teenage liars and truth tellers. The findings revealed that teenage offenders were significantly more accurate in their credibility judgments than teenage non-offenders. However, the offenders' impressive accuracy rates were not as a consequence of using valid cues to deceit. The feedback hypothesis helps to explain why the offenders were more accurate in their decisions: Operating within a criminal environment may mean that teenage offenders frequently lie and are lied to. Consequently, they receive more feedback than non-offenders regarding the effectiveness of their lies as well as how successful they are at detecting lies. As a result, their lie detection ability improves. The current study suggests moving away from individual deceptive cues as predictors of deceit towards a more intuitive and holistic approach to lie detection, such as the Brunswikian Lens Model. 


\section{Teenage Offenders' Ability to Detect Deception in Their Peers}

Research has shown that perceived experts in the field of lie detection often perform no better than lay individuals when detecting deceit (DePaulo \& Pfeifer, 1986; Ekman \& O’Sullivan, 1991; Kraut \& Poe, 1980; Vrij, 2008). In contrast, studies suggest that adult incarcerated criminals exhibit better lie detection skills than experts and lay people (e.g. Hartwig, Granhag, Stromwall, \& Andersson, 2004).

Additionally, criminals are more likely, than non-criminals, to hold beliefs about cues to deceit that more accurately mirror valid cues to deceit (Granhag, Andersson, Stromwall \& Hartwig, 2004; Vrij \& Semin, 1996). There is an abundance of literature available on the deceptive cues (both nonverbal and verbal) associated with lying and the detection of lies in adulthood. However, research in this area with teenage participants is underrepresented. This is particularly true of the abilities of teenage offenders to detect deception. The current study is the first to look at both the behavioural cues exhibited by teenagers who are lying and telling the truth and the ability of teenage offenders to detect deception in their peers. To do this, we recruited teenage offenders, living within the community, in an attempt to establish whether their deception detection ability develops through their teenage years and prior to custodial incarceration. 


\section{Deception detection accuracy: Offenders vs. non-offenders}

Human performance at detecting deceit rarely exceeds 60\% (Vrij, 2008). In comparison studies, offenders have shown significantly higher accuracy scores (approximately 65.4\%) than non-offenders who achieve an accuracy rate of no better than chance level (50\%) (Hartwig et al., 2004). Hogarth (2001) proposed that mere experience of a task (e.g., having to detect lies frequently) is not enough to improve performance. Instead, relevant outcome feedback must also be present to improve individual accuracy. Lie detection feedback may act as a catalyst for offenders, who are more likely to exhibit and face deceptive behaviour (DePaulo \& Pfeifer, 1986). For example, offenders, unlike nonoffenders, are likely to receive feedback about whether or not their deceptive strategies are effective. If they are effective, they will avoid being caught by the authorities and they will be able to successfully commit criminal acts involving fraud and deceit. If they are not effective in their deception strategies they will be more likely to be caught and less likely to successfully undertake their criminal activity. Criminals may also develop self-preservation strategies through feedback from repetitive interrogations (Hartwig et al., 2004). Offenders are therefore seen to have more insight into the psychology of deception (Granhag et al., 2004). The facilitative aspect of feedback appears important in developing deception detection ability. Simply making judgments about veracity does not increase lie detection accuracy (Ekman \& O'Sullivan, 1991). It is the feedback of knowing if those judgments were accurate that can act as a mechanism for increased lie detection accuracy. Suggestions have been made that the feedback criminals receive through interrogation may increase their particular deception strategies (Hartwig et al., 2004), allowing for a process of accommodation to build a successful knowledge base. It is proposed that it is this knowledge that increases their deception detection abilities. As such, it was predicted that teenage 
offenders in the current study would show better deception detection ability than teenage non-offenders (Hypothesis 1).

\section{Truth and lie biases}

Research suggests that individuals are more likely to identify truthful statements than deceptive ones due to their predominant exposure to truthful discourse (Vrij, 2008), which is referred to as a 'truth bias'. Levine, Park and McCornack (1999) were the first to identify a substantial truth bias in their research, with participants more likely to identify targets as honest instead of deceitful, a finding replicated over the intervening years (see Vrij, 2008 for a review). A meta-analysis identified that, on average, individuals tend to correctly identify truths in $61 \%$ of cases, and lies in $47 \%$ of cases (Bond \& DePaulo, 2006), which supports a 'veracity effect'. Elaad (2003) proposed that the environment plays a key role in adapting biases towards veracity for most people. That is, individuals frequently work and socialise with others and so there is a requirement that, on the whole, most people take what others say at face value (Levine, 2014). Should people start to question, scrutinise and doubt every assertion heard then cooperation and trust will break down.

However, this truth bias may not apply to criminals who are more likely to lie in high stakes situations and to exhibit suspicion towards others. Such findings were found by Hartwig et al. (2004) when comparing the deception detection ability of prison inmates with college students. Although Hartwig et al. (2004) found no significant difference between the overall detection accuracy of students $(57.7 \%)$ and prison inmates $(65.4 \%)$, the identification of deceptive statements was particularly high for prison inmates (88.5\%) compared with students $(65.4 \%)$. Both the prison inmates and the students found it difficult to correctly identify truthful statements $(42.3 \%$ and $50 \%$ respectively). Overall, prison inmates exhibited a lie bias; thus were better at identifying deceptive statements compared to truthful ones. This 
enhanced ability to detect deceptive statements is also documented by Bond, Malloy, Arias, Nunn and Thompson (2005), who looked at biases in prison and non-prison contexts, with younger and older adults. Younger prison inmates were classified as accurate deception identifiers, however they were also shown to exhibit a lie bias. This suggests that their unusual social environment led them to develop a 'reversed veracity effect' (Bond et al., 2005). In the current study, it was hypothesised that teenage non-offenders would exhibit a truth bias in their credibility judgments whereas teenage offenders would exhibit a lie bias in their credibility judgments (Hypothesis 2).

\section{Believed vs. actual cues to deceit}

Commonly held misconceptions about the behaviours that indicate deception can affect performance (Hartwig \& Bond, 2011). Such cues that lay individuals believe to be indicative of lying (e.g., lack of eye contact and fidgeting) are often not actual cues to deceit. Both believed and actual cues to deceit have been thoroughly documented and meta-analyses consistently reveal a mismatch between the two (e.g., Akehurst, Köhnken, Vrij \& Bull, 1996; DePaulo et al., 2003; Vrij, 2008). If detectors were to refer to a different set of cues, then lie detection ability should increase (Hartwig \& Bond, 2011).

Meta-analyses reveal very few actual nonverbal indicators of lying (DePaulo et al., 2003; Vrij, 2008). The most reliable being an increase in voice pitch, duration of response latency (the time between the end of a question and the beginning of an answer) and a decrease in hand/arm movements and foot/leg movements (DePaulo et al., 2003, Vrij, 2008). In a meta-analysis by Sporer and Schwandt (2006), only two out of nine indicators were associated with deception in weighted analysis (voice pitch and response latency). In addition, the idiosyncrasy of human behaviour compounds this lack of reliable cues to deceit with no single behaviour exhibited every time an individual lies (Vrij, 2008). 
Inaccurate/Invalid perceptions of lie behaviours are not only true of student populations, but have also been found for social workers, police officers and teachers (Stromwall \& Granhag, 2003; Vrij, Akehurst \& Knight, 2006).

Research by Forrest, Feldman and Tyler (2004) demonstrated that when participants were more accurate/valid in their beliefs regarding actual cues to deception, they increased their lie detection ability. Interestingly, Granhag et al. (2004) and Vrij and Semin (1996) found that criminals held more accurate/valid beliefs, in general, regarding cues to deceit and this is likely to contribute, along with more day-to-day feedback, to their superior lie detection accuracy.

Vrij and Granhag (2012) have discussed the need for research to look more at how questioning can enhance the elicitation of cues to deception, rather than a passive observing of behavioural cues displayed during such questioning. They suggest moving away from the use of video clips depicting truthful and deceptive discourse. The argument of the current paper is that whilst this approach is of course warranted, when looking at both 'offenders' and 'teenagers' as a population, research should not be too hasty as to jump directly to process based approaches before fully appreciating the extent to which a cue based approach may be used within teenage detectors.

In the current study, certain behaviours of the interviewees were coded for frequency or duration to assess whether or not there were any significant differences between truth tellers and liars. That is, we investigated whether or not there were any actual differences in behaviours that, for our sample, would be helpful in making credibility judgments. We then asked our participants (the teenage offenders and teenage non-offenders) which cues they used to make their credibility judgments. It was hypothesised that teenage offenders would 
be more likely than non- offenders to use accurate/valid cues to make accurate credibility judgments (Hypothesis 3).

\section{Method}

\section{Participants}

Youth support programme co-ordinators were emailed about the study. The coordinators then invited the young people on their programmes to volunteer for this study. Sixteen participants (eight males, eight females) between 13 and 18 years of age $(M=15$ years, $S D=1.71$ years) were recruited from the programmes to form the offender group. We asked the young people if they had been convicted of an offence and to list the transgressions for which they were convicted. Whilst a conviction was necessary for a participant to be categorised as an offender, most participants failed to disclose details of their offences. However, for those that did, offences included battery, theft, racial assault, arson, endangering life and criminal damage. The services managers for the youth support programmes consented to the teenagers participating because of the difficulty of obtaining parental consent. Participants themselves also completed informed consent forms.

A further 36 participants (12 males and 24 females) between 12 and 17 years $(M=$ 16.4 years, $S D=1.25$ years) were recruited from a secondary school ${ }^{1}$. Potential participants' parents gave consent for their children to participate, and the children themselves also completed informed consent forms.

\section{Design}

\footnotetext{
${ }^{1}$ The unequal sex ratio within the secondary school was a representation of the unequal female: male ratio within the classes that we were given access to.
} 
The first phase of the experiment comprised of a 2 (Offender Status: offender vs. nonoffender) x 2 (Veracity: truthful vs. deceptive) independent groups design. The dependent variables were participants' accuracy scores on the lie detection tasks (including accuracy for truths and lies separately).

For phase two, behavioural cues exhibited by truth tellers and liars were coded from the video recordings of the interviews. The behaviours that were coded were duration of response latency (in milliseconds), frequency of hand movements, frequency of foot movements and number of details included in interviewees' accounts. These behaviours were selected based on published findings by Vrij (2008) whose review suggests that these cues are the most reliable for use by lay persons (with no training in techniques such as CriteriaBased Content Analysis and Reality Monitoring). Previous meta-analyses suggest that response latencies are longer, frequency of hand movements and foot movements are fewer, and there is less detail included in the accounts of liars compared with the accounts of truth tellers. For interest, duration of eye contact was also coded as it was anticipated that participants would indicate that they had used this to judge credibility as it is often cited as a believed cue to deceit (Stromwall \& Granhag, 2003; Vrij, Akehurst \& Knight, 2006), but not an actual indicator of deceit (Vrij, 2008).

\section{Stimulus material}

All participants in the first phase of the study watched video clips of interviews with truth-telling and lie-telling teenagers. To create these truthful and deceptive clips, 12 young people who were not participants in the main study (five males and seven females, aged 14 to 18 years) were recruited as interviewees, via opportunity sampling. Six interviewees told the truth in their interviews and six were instructed to lie during their interviews. All 12 interviewees took part on the same day, within the same interview room, and were 
interviewed by the same person who was blind to the veracity condition of the interviewees. Deceptive interviewees were given an MP3 player to hide on their person; truth tellers were not. All interviewees were told that they would be questioned about the whereabouts of the MP3 player that had gone missing in the canteen earlier that day and instructed to deny the possession of the MP3 player. Therefore, truth tellers just had to tell the truth (because they did not have the MP3 player), whereas liars had to lie (because they were in possession of the MP3 player). A video camera recorded the interviews with a full-length shot of the interviewee; thus all of the body and facial movements of the interviewees were visible on screen. The interviewer was not in the shot, but could be heard. The interviewer interviewed each young person in turn asking about the whereabouts of the MP3 player using eight standardised questions (see Appendix 1). Interviewees were then debriefed. The video clips of truthful interviewees ranged from 65 seconds to 83 seconds $(M=74.83$ seconds $)$ and the six clips of interviewees who were lying ranged from 78 seconds to 90 seconds $(M=79.25$ seconds).

\section{Procedure}

Participants were each given an answer booklet and informed that they would see a number of interview clips, regarding the whereabouts of a stolen MP3 player. They were told that some individuals in the clips were hiding an MP3 player on their person and others were not. They were then informed that after each clip they would need to make a veracity judgment, indicating whether they believed the individual or not. It was stressed that there could be any combination of truths and lies (i.e., $100 \%$ truths or $100 \%$ lies or any combination of the two). This allowed for unbiased judgments based on participants' beliefs about the clips, rather than decisions based on how many truthful and deceptive clips there were thought to be. Furthermore, to manage expectations, participants were told that they 
would see 18 interview clips when they were actually only shown 12 clips. This was to reduce the likelihood that participants would guess there was a 50:50 ratio of lies to truths and adjust their judgments accordingly. As well as indicating whether they believed each interviewee to be lying or telling the truth, participants were also asked to indicate the verbal and nonverbal cues they used to help them make each veracity decision; participants were able to give open text responses with no structuring from the researchers.

The 12 interview clips were shown to participants via a laptop computer. Four DVDs were used for this experiment with each DVD presenting the 12 clips in a different sequence. Each DVD was shown an equal number of times. This methodology was used to reduce order and fatigue effects.

When participants had rated all 12 interview clips, they completed a questionnaire which was comprised of 14 questions relating to gender, age, any previous participation in psychology experiments and any previous offences that they had committed (number of times charged with an offence and number of times convicted).

\section{Coding behavioural cues}

A software system called Interact was used to code duration of response latency (time in ms from end of question to beginning of answer which was summed across each interview), frequency of hand movements, frequency of foot movements, quantity of detail (a score of 1 given to each piece of new information given) and duration of eye contact (time in ms summed across each interview) for truth tellers and liars. Two evaluators coded each of these five behaviours. Inter-rater reliability, calculated using Pearson's correlations, was very high for all behaviours: Duration of response latency in ms (summed across each interview), $r=.925, p<.001$; frequency of hand movements, $r=.995, p<.001$; frequency of foot movements, $r=.992, p<.001 ;$ number of details provided, $r=.955, p<.001 ;$ duration of 
eye contact in ms (summed across each interview), $r=.985, p<.001$. The mean ratings across the two evaluators were used for subsequent analyses.

\section{Results}

\section{Manipulation check}

It was not assumed that those participants recruited via the youth offending programme were offenders and that those recruited via the school were non-offenders. This was verified by examining all responses to the questions asked about previous criminal records. All 16 of the participants labelled young offenders indicated on their questionnaires that they had been charged and convicted of at least one crime. None of the 36 young nonoffenders indicated that they had been charged or convicted of a crime ${ }^{2}$.

\section{Accuracy rates}

To allow results to be compared with those of similar studies, percentage accuracy was computed for each group. Offenders, with $67 \%$ accuracy, performed significantly better than chance, binomial $p<.001$ whereas the non-offenders, with 50\% accuracy did not perform significantly better than chance, binomial $p=.68$. When looking at accuracy by veracity of statement, offenders correctly identified $60 \%$ of truthful statements and $73 \%$ of lies. Both these accuracy rates were significantly above chance level (binomial $p=.01$ and binomial $p<.001$ respectively). Non-offenders identified $49 \%$ of truthful statements and $51 \%$ of lies. Neither of these accuracy rates were significantly different from chance level (binomial $p=.65$ and binomial $p=.95$ respectively).

\footnotetext{
${ }^{2}$ Although our categorisation of offenders was via self-report, it is unlikely that the participants recruited via the school were neglecting to report any convictions as it was stressed to them that the information they gave could not be linked to them in any way.
} 
To test Hypothesis 1, a one-way MANOVA was calculated with Offender Status (offender vs. non-offender) as the independent variable and overall accuracy (number of correct decisions out of 12), accuracy for lie clips (number of correct decisions out of six) and accuracy for truth clips (number of correct decisions out of six) as the dependent variables. The MANOVA revealed a significant multivariate main effect for Offender Status, $F(2,49)=12.078, p=<.001, e t a^{2}=.953$. Additionally, significant univariate main effects for

Offender Status were obtained. Overall, young offenders were significantly more accurate ( $M$ $=8.00, S D=1.51,95 \% \mathrm{CI}[7.20,8.98]$ than young non-offenders $(M=6.00, S D=1.62,95 \%$ CI $[5.47,6.53]), F(1,50)=17.58, p=<.001, d=1.28$. For the lie clips, young offenders were significantly more accurate $(M=4.38, S D=0.72,95 \%$ CI $[3.90,4.86])$ than young nonoffenders $(M=3.08, S D=1.05,95 \%$ CI $[2.76,3.41]), F(1,50)=17.58, p=<.001, d=$ 1.44. Finally, for the truthful clips, young offenders were more accurate $(M=3.63, S D=$ $1.50,95 \% \mathrm{CI}[2.94,4.31])$ than young non-offenders $(M=2.92, S D=1.28,95 \% \mathrm{CI}[4.46$, 3.37]), but this was not significant, $F(1,50)=3.00, p=.089$.

\section{Signal detection analysis}

Meissner and Kassin (2002) have suggested that Signal Detection Theory (SDT) can be used to analyse the accuracy of credibility assessments. As such, the performance of our evaluators was calculated in terms of discrimination accuracy $\left(d^{\prime}\right)$ and response bias $(\beta)$. D prime $\left(d^{\prime}\right)$ is a pure measure of sensitivity; it measures the signal and the noise means in standard deviation units. It corrects for response bias and guessing. A value of 0 indicates evaluators showed an inability to distinguish liars from truth tellers. Values above 0 indicate an ability to distinguish liars from truth tellers, and negative values indicate response confusion (i.e., sampling error, such as providing a 'true' response when you actually intended to provide a 'lie' response, or vice versa (Stanislaw \& Todorov, 1999)). Beta $(\beta)$ is a 
measure of response bias (i.e., the tendency to respond 'truth' or 'lie'). A value of 1 means participants did not favour a particular response, a value greater than 1 means participants showed a bias towards a truth judgment, and a value less than 1 means that participants showed a bias towards a judgment that the interviewee was lying.

Table 1 shows the total number of hits, misses, false alarms and correct rejections obtained for the offender group and the non-offender group. A hit is a lie that is correctly identified as a lie, a miss is a lie which is incorrectly identified as a truth, a false alarm is a truth that is incorrectly identified as a lie and a correct rejection is a truth that is correctly identified as a truth. Using these figures, $d$ ' and $\beta$ could be calculated for each participant.

\section{INSERT TABLE 1 HERE}

An independent samples t-test was conducted with Offender Status (offender vs. nonoffender) as the independent variable and $d^{\prime}$ as the dependent variable. Young offenders were significantly better at distinguishing lies from truths $(M=.831, S D=.850)$, than young nonoffenders $(M=.016, S D=.783), t(50)=3.375, p=.001, d=.997$.

In a second level of analysis, $d$ ' values were compared to 0 (no ability to differentiate between truths and lies) using one-sample $t$ tests. The mean $d$ 'value for offenders was significantly greater than $0, t(15)=3.910, p=.001, d=2.02$; whereas the mean $d$ ' value for non-offenders was not significantly greater than $0, t(35)=.122, p=.904$. All these results and that of the MANOVA above lend support to Hypothesis 1 that teenage offenders would be significantly better able to discriminate between truth tellers and liars than teenage nonoffenders.

An independent samples t-test was conducted with Offender Status (offender vs. nonoffender) as the independent variable and $\beta$ as the dependent variable. There was no significant difference between offenders $(M=1.102, S D=.327)$ and non-offenders $(M=$ $1.038, S D=.208)$ in terms of response bias, $t(46)=.815, p=.419$. 
Using one-sample $t$ tests, $\beta$ values for the offender and non-offender groups were compared to 1 . A value of 1 means participants did not favour a particular response, $>1$ means participants showed a truth bias and $<1$ means participants showed a lie bias. The mean $\beta$ value for offenders was not significantly less than $1, \mathrm{t}(13)=1.165, \mathrm{p}=.265$ and the mean $\beta$ value for non-offenders was not significantly greater than $1, t(33)=1.059, p=.297$. Therefore no support was found for Hypothesis 2 that teenage non-offenders would exhibit a truth bias in their credibility judgments whereas teenage offenders would exhibit a lie bias in their credibility judgments.

\section{Valid cues to deception}

To determine whether the five behaviours (response latency, hand movements, foot movements, quantity of detail and eye contact) that had been rated by two independent evaluators, were predictive of actual truth status, a one-way ANOVA was conducted. The independent variable was the truth status of the interviewees (Liars or Truth Tellers) and the duration of response latency, frequency of hand movements, frequency of foot movements, quantity of details and duration of eye contact were the dependent variables. Liars had significantly longer response latencies $(M=6.79, S D=1.51,95 \%$ CI $[5.20,8.37])$, than truth tellers $(M=4.43, S D=1.12,95 \%$ CI $[3.25,5.60]), F(1,10)=9.44, p=.012, d=-1.77$; liars had significantly fewer hand movements $(M=2.08, S D=2.87,95 \%$ CI $[-929,5.07])$, than truth tellers $(M=8.58, S D=4.64,95 \%$ CI $[3.71,13.45]), F(1,10)=8.51, p=.015, d=1.68$; liars had significantly fewer foot movements $(M=4.33, S D=3.15,95 \%$ CI $[1.02,7.65])$, than truth tellers $(M=15.17, S D=11.63,95 \% \mathrm{CI}[2.97,27.37]), F(1,10)=4.85, p=.015, d$ $=1.27$ and liars provided significantly fewer details $(M=6.75, S D=4.01,95 \%$ CI $[2.54$, $10.96])$, than truth tellers $(M=13.33, S D=4.78,95 \%$ CI $[8.32,18.35]), F(1,10)=6.68, p=$ $.027, d=1.49$. Liars showed longer eye contact $(M=37.19, S D=5.20,95 \%$ CI [31.73, 
42.65]), than truth tellers $(M=35.26, S D=3.32,95 \% \mathrm{CI}[31.74,38.71])$ but this was not significant, $F(1,10)=.610, p=.453$.

As a result of these findings, it was appropriate to analyse whether or not offenders, who were more accurate in their credibility judgments than their non-offending counterparts, had used valid cues to make their decisions more often than the non-offenders.

\section{Believed cues to deception}

All participants were invited to indicate, via an unstructured free report, which behavioural cues they used when making their decisions about veracity. Decisions were split into accurate and inaccurate decisions. That is, whether or not an interviewee was correctly classified as a truth teller or a liar. Researchers then analysed each free report and categorised as present, or absent, the four behaviours that had been found, for this sample, to be indicative of deceptive behaviour. That is, participants' responses were coded for the mention of response latency, hand movements, foot movements and the quantity of detail given by interviewees. Although there were no significant differences in the amount of eye contact for truthful and lying interviewees, this cue was also coded to see if we could replicate the findings of previous research that suggests this is a popular believed cue to deceit.

No participants stated that they had used foot movements to help them make their credibility decisions. Interestingly, both Offenders and Non-Offenders cited eye contact as the most frequently used cue within the subset of cues that were coded. This was the case regardless of whether the participants had made accurate or inaccurate decisions about the credibility of the interviewees. Table 2 illustrates the number of times response latency, hand movements, foot movements, quantity of detail and eye contact were mentioned by participants as a function of whether or not they made an accurate credibility judgment or not. 


\section{INSERT TABLE 2 HERE}

To test Hypothesis 3, that teenage Offenders would be more likely than NonOffenders to use valid cues to make accurate credibility judgments, a one-way ANOVA was conducted. Only the behaviours noted for accurate judgments were included in the analysis. The independent variable was the Offender Status of the participants and mentions of duration of response latency and frequency of hand movements were the dependent variables. As mentioned above, no participants mentioned foot movements so this was not included in the analysis. Furthermore, quantity of detail was only mentioned for inaccurate decisions so this was not included in the analysis. Finally, mentions of eye contact were not included because, although participants often mentioned them, they are not actually valid cues to deception for this sample of interviewees.

When making accurate decisions, Offenders cited longer response latencies significantly less often $(M=0.53, S D=0.26,95 \%$ CI $[0.01,0.09])$, than non-offenders $(M=$ $0.12, S D=0.32,95 \%$ CI $[0.07,0.16]), F(1,334)=3.89, p=.049, d=-0.21$. For accurate decisions, offenders cited fewer hand movements $(M=0.03, S D=0.17,95 \% \mathrm{CI}[0.00,0.06])$, less often than non-offenders $(M=0.07, S D=0.26,95 \%$ CI $[0.04,0.11])$, but this was not significant, $F(1,334)=2.73, p=.099$. Therefore, no support was found for Hypothesis 3 that young offenders would be more likely than non-offenders to use valid cues to make accurate credibility judgments. In fact the opposite was true. Non-offenders, more so than offenders, were more likely to mention valid cues to deception when they made accurate credibility judgments.

\section{Discussion}

Before the current study, no investigation into the lie detection capabilities of teenage offenders had been conducted. The current study furthers the research into criminal liedetection accuracy and attempts to make a link between behavioural cues that are actually 
discriminatory and those that are used by observers. The current study highlights above average lie-detection skills in teenage offenders who outshone their non-offending counterparts.

\section{Deception detection accuracy: Offenders vs. non-offenders}

As predicted in Hypothesis 1, teenage offenders showed a significantly higher overall accuracy rate for veracity than teenage non-offenders. They identified $60 \%$ of truths and $73 \%$ of lies, with an overall accuracy rate of $67 \%$. Both their identification of truths and lies were significantly better than chance. In comparison, the non-offenders achieved similar hit rates for truths and lies and an overall accuracy rate of only $50 \%$ which was not significantly better than chance. The current findings differ from those of Hartwig et al. (2004) who found no significant difference between the overall lie detection accuracy of student participants and prison inmates.

This, in part, may be explained by the feedback hypothesis. The teenage offenders in the current study exhibited good deception detection abilities and this may be due to their experience within a deceptive criminal environment. Our teenage offenders may have developed self-preservation strategies (Hartwig et al., 2004) during investigative interviews with police officers and during interactions with their contemporaries. That is, they may have been able to see which of their own deceptive strategies were successful leading them to be better able to judge the credibility of others. This supports the idea of a wider understanding of deception (Granhag et al., 2004).

\section{Truth and lie biases}

The current findings differ from previous research (e.g., Levine et al., 1999; Porter, ten Brinke, \& Gustaw, 2010) in that no truth bias was found for the teenage non-offenders. 
Furthermore, no bias (truth or lie) was found for the teenage offenders and therefore Hypothesis 2 was not supported. Whilst the general findings are that individuals are more likely to have a truth bias due to predominant exposure to truthful discourse (Vrij, 2008), the current findings propose that there is no truth or lie bias for either non-offenders or young offenders. This suggests that the 'veracity effect' (Bond \& DePaulo, 2006), which implies that individuals tend to have a higher ability to detect truths over lies, may not develop until adulthood. Furthermore, the teenage offenders in the current study did not have a pronounced lie bias as per the findings of Hartwig et al. (2004). Whilst Hartwig et al, (2004) did not find offenders to be better at detecting deception than non-offenders overall, they did have a particularly high ability to detect lies $(88.5 \%)$. This indicates that in the current study, the teenage offenders' inflated ability to detect deception might have been due to the fact that they did not exhibit a truth or lie bias.

\section{Cues to deception}

We found that liars exhibited significantly longer response latencies than truth tellers. Vrij's (2008) review suggested that liars, compared to truth tellers do tend to wait for longer before starting their answers to questions (e.g., Farrow et al., 2003; Gregg, 2007; Johnson Jr., Barnhardt \& Zhu, 2003; Langleben et al., 2005). We also found that liars exhibited significantly fewer hand movements, and significantly fewer foot movements than truth tellers again supporting Vrij's (2008) review of the literature. In the current research, liars provided significantly fewer details than truth tellers. This is in line with the findings of DePaulo et al. (2003), Granhag, Vrij and Verschuere (2014) and Blandón-Gitlin, Fenn, Masip and Yoo, (2014) who suggest that with the increased cognitive effort of deception, liars are less likely to be able to provide as many details as truth tellers. 
Hypothesis 3 suggested that young offenders' enhanced ability to detect deceit may be as a result of, not only receiving more feedback, but also using valid cues to deception rather than invalid cues. Interestingly, the current study suggested that offenders do not make more accurate judgments using valid cues. The cue predominantly cited, by offenders and nonoffenders, for accurate decisions, eye-related behaviours, was not actually a behaviour that significantly discriminated our truth tellers from our liars. This supports the findings of Granhag et al. (2004), who found that both students and prison inmates held stereotypical and inaccurate beliefs about cues indicative of lying. Elaad (2009) also found that criminals held stereotypical beliefs regarding cues to deception. However, it does not support Vrij and Semin (1996) who found that prisoners had more accurate beliefs regarding valid cue usage in lie detection. It is evident from the current findings that invalid cues to deception were used by offenders when making some of their accurate credibility judgments. In sum, no clear picture has emerged in terms of the behavioural cues used to make accurate and inaccurate credibility judgments. It seems that those who make more correct judgments are not necessarily using useful cues.

Perhaps some explanation lies within an intuitive approach to the detection of deception (Hartwig \& Bond, 2011). It is likely that some of the skill individuals use to detect deceptive statements is a result of higher cognitive processes that are complex to evaluate and measure. Moreover, verbal explanations elicited from research participants are never able to fully represent complex mental processes due to a lack of introspective access (Nisbett \& Wilson, 1977). It is, therefore, hard to be confident that the cues our participants were reporting were representative of their decision-making strategies. The fact that the teenage offenders in the current study were able to detect 'lies' at a rate of $73 \%$ but appeared to use very few valid cues to deceit indicates that there were other processes involved, which may be "partially implicit and automatic" (Hartwig \& Bond, 2011, pg. 644). What is interesting in 
the context of the current study is that Hartwig and Bond (2011) discuss intuitiveness as a result of a lifetime of experience (of predominantly truthful discourse). However, our relatively young offenders had an average age of 15 years. This suggests that a criminal environment may somehow compensate for a lifetime of experience.

The Brunswikian Lens Model allows for a theoretical understanding of people's deception detection abilities (Hartwig \& Bond, 2011). This Model incorporates a) the predictability of interviewees' deceptiveness based on their actual behaviour, b) the predictability of the interviewees' perceived deceptiveness, and c) the matching of cue-based predictions of actual deceptiveness with cue-based predictions of apparent deceptiveness. This iterates the notion of an interplay of factors that may be too complex to be analysed with a simple 'observe and report' method, commonly central to lie detection research (including the current study). Whilst the current data has not been analysed with the Brunswikian Lens Model approach, this is a suggestion for future research to investigate the multifaceted processes of lie detection in a teenage sample. Teenage lies and truths remain an understudied domain in terms of verbal and nonverbal behavioural cues.

Limitations of the current study included the unequal sample sizes for each condition (as it was difficult to recruit the young offender sample) and the relatively small sample sizes. During analysis, steps were taken to make sure that the correct statistical assumptions were made due to the small and unequal sample sizes, but further research should explore whether the findings remain the same even when more young offenders, and more equal samples sizes, are recruited. Our non-offender sample comprised an unequal sex ratio of $33 \%$ males and $67 \%$ females. However, previous findings show no gender differences when it comes to detecting deception (Ekman \& O’Sullivan, 1991; Zuckerman, DePaulo, \& Rosenthal, 1981). 
Vrij and Granhag (2012) discuss their reservations with the use of video clips within deception research due to their lack of relativity to the way in which investigators actually assess deception. They argue that investigators should concentrate on the active processes used when making veracity judgments rather than relying on passive observation. ten Brinke and Porter (2012) argue that whilst visual cues to deception are, in part, overshadowed by the encouraged development of more diagnostic verbal cues (Vrij and Granhag, 2012), the use of numerous visual cues can be beneficial if used by an informed investigator. Within the current study, the experiences of the young offenders may act as a catalyst for such 'informed' knowledge leading to more pronounced deception detection abilities. This may therefore form a basis for the development of understanding into the 'process' of deception detection within teenage offenders.

Motivation in laboratory studies is a controversial subject. However, it is assumed that the same theoretical principles apply regardless of whether motivation is high or low, because the mechanisms used to detect deceit remain the same. The liars in the current study told lowstake lies; that is there was little to no consequence of the interviewee not convincing the interviewer of their truthfulness. It is generally noted that high-stake lies are in fact easier to detect than low stake lies (Lane \& DePaulo, 1999; Vrij, 2000; Vrij, Harden, Terry, Edward, $\&$ Bull, 2001) and that liars who have high motivation are easier to detect than those with low motivation (DePaulo, Blank, Swaim, \& Hairfield, 1992). In essence, this may mean that lie detection in laboratory situations is harder than in field studies.

In summary, the current study revealed a high lie detection accuracy score for the sample of young offenders with no accompanying lie or truth bias. The findings suggest that it may be the criminal environment that facilitates the development of lie-detection ability before custodial sentences are served. Exactly what it is that aids this ability is questionable 
and whilst feedback from everyday interactions provides one possible explanation, more research should further investigate this finding, by integrating concepts from more computational approaches, such as those proposed by Hartwig and Bond (2011).

\section{References}

Akehurst, L., Köhnken, G., Vrij, A., \& Bull, R. (1996). Lay Persons' and Police Officers' Beliefs Regarding Deceptive Behaviour. Applied Cognitive Psychology, 10(6), 461471. doi:10.1002/(SICI)1099-0720(199612)10:6<461::AID-ACP413>3.0.CO;2-2

Blandón-Gitlin, I., Fenn, E., Masip, J., \& Yoo, A. H. (2014). Cognitive-load approaches to detect deception: searching for cognitive mechanisms. Trends in Cognitive Sciences, 18(9), 441-444. doi:10.1016/j.tics.2014 .05.004

Bond, C. F., \& DePaulo, B. M. (2006). Accuracy of deception judgments. Personality and Social Psychology Review, 10(3), 214-234. doi:10.1207/s15327957pspr1003_2

Bond, G. D., Malloy, D. M., Arias, E. A., Nunn, S. N., \& Thompson, L. A. (2005). Liebiased decision making in prison. Communication Reports, 18(1-2), 9-19. doi:10.1080/08934210500084180

DePaulo, B. M., Blank, A. L., Swaim, G. W., \& Hairfield, J. G. (1992). Expressiveness and Expressive Control. Personality and Social Psychology Bulletin, 18(3), 276-285. doi:10.1177/0146167292183003

DePaulo, B. M., \& Pfeifer, R. L. (1986). On-the-Job Experience and Skill at Detecting Deception1. Journal of Applied Social Psychology, 16(3), 249-267. doi:10.1111/j.1559-1816.1986.tb01138.x

Ekman, P., \& O'Sullivan, M. (1991). Who can catch a liar? American Psychologist, 46(9), 913-920. doi:10.1037/0003-066X.46.9.913

Elaad, E. (2003). Effects of feedback on the overestimated capacity to detect lies and the 
underestimated ability to tell lies. Applied Cognitive Psychology, 17(3), 349-363. doi: 10.1002/acp.871

Elaad, E. (2009). Lie-detection biases among male police interrogators, prisoners, and laypersons. Psychological Reports, 105(3 Pt 2), 1047-1056. http://doi.org/10.2466/PR0.105.F.1047-1056

Farrow, T. F., Reilly, R., Rahman, T. A., Herford, A. E., Woodruff, P. W., \& Spence, S. A. (2003). Sex and personality traits influence the difference between time taken to tell the truth or lie. Perceptual and Motor Skills, 97(2), 451-460. doi:10.2466/pms.2003.97.2.451

Forrest, J. A., Feldman, R. S., \& Tyler, J. M. (2004). When accurate beliefs lead to better lie detection1. Journal of Applied Social Psychology, 34(4), 764-780. doi:10.1111/j.1559-1816.2004.tb02569.x

Granhag, P. A., Andersson, L. O., Strömwall, L. A., \& Hartwig, M. (2004). Imprisoned knowledge: Criminals' beliefs about deception. Legal and Criminological Psychology, 9(1), 103-119. doi:10.1348/135532504322776889

Granhag, P. A., Vrij, A., \& Verschuere, B. (2014). Detecting Deception: Current Challenges and Cognitive Approaches. John Wiley \& Sons.

Gregg, A. P. (2007). When vying reveals lying: The timed antagonistic response alethiometer. Applied Cognitive Psychology, 21(5), 621-647. doi:10.1002/acp.1298

Hartwig, M., \& Bond, C. F. (2011). Why do lie-catchers fail? A lens model meta-analysis of human lie judgments. Psychological Bulletin, 137(4), 643-659. doi:10.1037/a0023589

Hartwig, M., Granhag, P. A., Strömwall, L. A., \& Andersson, L. O. (2004). Suspicious Minds: Criminals' ability to Detect Deception. Psychology, Crime and Law, 10(1), 83-95. doi:10.1080/1068316031000095485 
Hogarth, R. M. (2001). Educating Intuition. University of Chicago Press.

Johnson Jr., R., Barnhardt, J., \& Zhu, J. (2003). The deceptive response: effects of response conflict and strategic monitoring on the late positive component and episodic memory-related brain activity. Biological Psychology, 64(3), 217-253. doi:10.1016/j.biopsycho.2003.07.006

Kraut, R. E., \& Poe, D. B. (1980). Behavioral roots of person perception: The deception judgments of customs inspectors and laymen. Journal of Personality and Social Psychology, 39(5), 784-798. doi:10.1037/0022-3514.39.5.784

Lane, J. D., \& DePaulo, B. M. (1999). Completing Coyne's cycle: Dysphorics' ability to detect deception. Journal of Research in Personality, 33(3), 311-329. doi:10.1006/jrpe.1999.2253

Langleben, D. D., Loughead, J. W., Bilker, W. B., Ruparel, K., Childress, A. R., Busch, S. I., \& Gur, R. C. (2005). Telling truth from lie in individual subjects with fast eventrelated fMRI. Human Brain Mapping, 26(4), 262-272. doi:10.1002/hbm.20191

Levine, T. R. (2014). Truth-Default Theory (TDT) A Theory of Human Deception and Deception Detection. Journal of Language and Social Psychology, 33(4), 378of Lan

Levine, T. R., Park, H. S., \& McCornack, S. A. (1999). Accuracy in detecting truths and lies: Documenting the "veracity effect." Communications Monographs, 66(2), 125-144. doi:10.1080/03637759909376468

Meissner, C. A., \& Kassin, S. M. (2002). "He's guilty!”: Investigator bias in judgments of truth and deception. Law and Human Behavior, 26(5), 469-480. doi:10.1023/A:1020278620751

Nisbett, R. E., \& Wilson, T. D. (1977). Telling more than we can know: verbal reports on mental processes. Psychological Review, 84(3), 231.

Porter, S., ten Brinke, L., \& Gustaw, C. (2010). Dangerous decisions: the impact of first 
impressions of trustworthiness on the evaluation of legal evidence and defendant culpability. Psychology, Crime \& Law, 16(6), 477-491.

doi:10.1080/10683160902926141

Sporer, S. L., \& Schwandt, B. (2006). Paraverbal indicators of deception: a meta-analytic synthesis. Applied Cognitive Psychology, 20(4), 421-446. doi:10.1002/acp.1190

Stanislaw, H., \& Todorov, N. (1999). Calculation of signal detection theory measures. Behavior research methods, instruments, \& computers, 31(1), 137-149.

Strömwall, L., \& Granhag, P. A. (2003). How to detect deception? Arresting the beliefs of police officers, prosecutors and judges. Psychology, Crime and Law, 9(1), 19-36. doi:10.1080/10683160308138

Strömwall, L. A., Granhag, P. A., \& Hartwig, M. (2004). Practitioners' beliefs about deception. In P. -A \& L. Str (Eds.), The detection of deception in forensic contexts (pp. 229-250). New York, NY, US: Cambridge University Press.

ten Brinke, L., \& Porter, S. (2012). Cry me a river: Identifying the behavioral consequences of extremely high-stakes interpersonal deception. Law and Human Behavior, 36(6), 469.

Van Bockstaele, B., Verschuere, B., Moens, T., Suchotzki, K., Debey, E., \& Spruyt, A. (2012). Learning to Lie: Effects of Practice on the Cognitive Cost of Lying. Frontiers in Psychology, 3. doi:10.3389/fpsyg.2012.00526

Vrij, A. (2000). Detecting lies and deceit: The psychology of lying and implications for professional practice. Wiley \& Sons.

Vrij, A. (2008). Detecting lies and deceit: Pitfalls and opportunities. John Wiley \& Sons.

Vrij, A., Akehurst, L., \& Knight, S. (2006). Police officers', social workers', teachers' and the general public's beliefs about deception in children, adolescents and adults. Legal and Criminological Psychology, 11(2), 297-312. doi:10.1348/135532505X60816 
Vrij, A., \& Granhag, P. A. (2012). Eliciting cues to deception and truth: What matters are the questions asked. Journal of Applied Research in Memory and Cognition, 1(2), 110117.

Vrij, A., Harden, F., Terry, J., Edward, K., \& Bull, R. (2001). The influence of personal characteristics, stakes and lie complexity on the accuracy and confidence to detect deceit. In R. Roesch, R. R. Corrado \& R. J. Dempster (Eds.), Psychology in the courts: International advances in knowledge (pp. 289-304). London, UK: Routledge.

Vrij, A., \& Semin, G. R. (1996). Lie experts' beliefs about nonverbal indicators of deception. Journal of Nonverbal Behavior, 20(1), 65-80. doi:10.1007/BF02248715

Zuckerman, M., DePaulo, B. M., \& Rosenthal, R. (1981). Verbal and nonverbal communication of deception. Advances in Experimental Social Psychology, 14(1), 59. 
Table 1. Total frequency of hits, misses, false alarms, correct rejections for offenders and non-offenders.

\begin{tabular}{cccccc}
\hline & Hit & Miss & False Alarm & $\begin{array}{c}\text { Correct } \\
\text { Rejection }\end{array}$ & Total \\
& & & & 58 & 192 \\
\hline Offenders & 69 & 27 & 38 & 105 & 432 \\
Non-offenders & 110 & 106 & 111 & 163 & 624 \\
Total & 179 & 133 & 149 & \\
\hline
\end{tabular}


Table 2. Percentage of cited valid cues to deceit

\begin{tabular}{ccccc}
\hline \multirow{2}{*}{ Behaviour } & \multicolumn{2}{c}{ Offenders } & \multicolumn{2}{c}{ Non offenders } \\
\hline & Accurate & Inaccurate & Accurate & Inaccurate \\
& decision & decision & decision & decisions \\
Response latency & $5.3 \%$ & $3.3 \%$ & $11.7 \%$ & $6.9 \%$ \\
Hand movements & $3.1 \%$ & $4.9 \%$ & $7.3 \%$ & $7.9 \%$ \\
Foot movements & $0 \%$ & $0 \%$ & $0 \%$ & $0 \%$ \\
Quantity of details & $0 \%$ & $1.6 \%$ & $0 \%$ & $1 \%$ \\
Eye contact & $10.7 \%$ & $13.1 \%$ & $16.5 \%$ & $19.7 \%$
\end{tabular}




\section{Appendix 1: Interview questions}

1. Do you have the ipod in your possession?

2. Are you telling the truth?

3. Tell me exactly what you do have in your possession.

4. You forgot to mention the ipod didn't you?

5. Are you telling me that you do not have the ipod in your possession?

6. Are you absolutely sure that you are telling me the truth?

7. So to make sure we have this absolutely clear, you are $100 \%$ sure that you do not have the ipod in your pockets somewhere?

8. Just recap for me one more time, what do you have in your pockets at the moment? 